\title{
Myasthenia gravis occurring in twins
}

\author{
T. NAMBA ${ }^{1}$, M. S. SHAPIRO, N. G. BRUNNER, AND D. GROB \\ From the Department of Medicine, Maimonides Medical Center and State University of New York Downstate \\ Medical Center, Brooklyn, New York, U.S.A.
}

SUMMARY Myasthenia gravis in one member each of two sets of twins is described. A 17 year old girl developed generalized myasthenia gravis at the age of 14 years, while her monozygotic twin sister has remained in good health during a three year period of observation. Another patient was a 19 year old woman with the onset of generalized myasthenia gravis at the age of 11 years, and her dizygotic twin sister has been in good health.

Myasthenia gravis has been described in 13 sets of monozygotic twins, seven sets of dizygotic twins, and one set of twins with undetermined zygosity. Both members of twins were affected in five sets of monozygotic twins and one set of twins with undetermined zygosity, and only one twin was affected in the remaining sets of twins. Occurrence of myasthenia gravis in both members of monozygotic twins and in none of dizygotic twins, and frequent familial occurrence of the disease suggest the role of a genetic factor in the pathogenesis of this disease.

Familial occurrence of myasthenia gravis has been recognized since Oppenheim's description in 1898. The cause of familial myasthenia has not been established, but it may be due to genetic inheritance, coincidental association, or infections or environmental factors. This paper reports the development of myasthenia gravis in one member each of two sets of twin sisters, and reviews the occurrence of myasthenia gravis in twins and the role of genetic factors in this disease.

\section{CASE 1}

Case 1 is a 17 year old white girl of Italian descent who was in good health until the age of 14 , when she developed ptosis of the left eye, followed within a few days by ptosis of the right eye and intermittent diplopia. During the following three weeks the patient developed difficulty in chewing and sagging of the jaw. During the next three months there occurred slurred nasal speech, weakness of the arms and legs, difficulty in swallowing, and weight loss of $13 \mathrm{lb}$. $(6 \mathrm{~kg})$. She was at her best strength on awakening, and became progressively weaker towards evening.

The patient was examined four months after the onset of symptoms. There was bilateral ptosis of moderate degree which increased on upward deviation of the eyes for one minute. Upward deviation of the eyes was moderately limited and lateral deviation slightly limited. There was diplopia on lateral gaze. The orbicularis oculi and orbicularis oris muscles were moderately weak, and

${ }^{1}$ Address for reprints: Dr. Tatsuji Namba, Maimonides Medical Center, Brooklyn, New York 11219, U.S.A. other facial muscles slightly weak. Mastication was strong initially, but fatigued rapidly. The voice was nasal and speech slurred. There was generalized weakness of the trunk and extremity muscles of moderate degree. The grip strength of each hand was $9 \mathrm{~kg}$. When the patient was lying supine she could raise her head for five seconds, her arms for 10 seconds, the right leg for 15 seconds, and the left leg for seven seconds.

After the intravenous injection of $10 \mathrm{mg}$ edrophonium chloride there was prompt improvement in ptosis, ocular motility, facial muscles, mastication, voice, and general strength. Grip strength of each hand increased to $22 \mathrm{~kg}$. The head could be elevated for 22 seconds, the arms for 25 seconds, and each leg for 25 seconds.

In the basal state, electromyographic examination of the right first dorsal interosseous muscle revealed a myasthenic reaction, with rapid decrease of amplitude of action potentials evoked by stimulations of the ulnar nerve at $25 / \mathrm{sec}$, and post-tetanic facilitation. Conduction velocity of this and other motor nerves, and muscle action potentials obtained by needle electrode, were normal. Serum protein-bound iodine was $6.0 \mu \mathrm{g} / 100 \mathrm{ml}$. and radioiodine uptake was $40 \%$. Pulmonary function tests were normal. There was no mediastinal mass by $x$-ray examination.

The patient was given pyridostigmine bromide, $120 \mathrm{mg}$ orally every four hours when awake, with moderate relief of symptoms. Her condition has remained essentially unchanged for the past three years.

The patient's father, age 56 years, and mother, age 47 years, were in good health. The patient had a twin sister who was in good health, with normal strength, electromyogram, and response to intravenous curare, and who has remained well during the three years of observation. The height, body build, and general appear- 
ance of the twins were similar, but their facial expressions were different: the patient in the basal state had myasthenic facies, with ptosis and sagging jaw, while her sister had a lively expression. When the patient received pyridostigmine, her facial expression improved and was more similar to her sister's.

The blood types of the twins were identical: A, MNSs, $\mathrm{CDe} / \mathrm{cde}, \mathrm{K}-$, $\mathrm{Fy}(\mathrm{a}-)$, and $\mathrm{Jk}(\mathrm{a}+)$. The total finger ridge count was 178 in the patient, and 184 in her sister. The total maximal axial triradius angle was $84^{\circ}$ in the patient, and $77^{\circ}$ in her sister. The probability of the twins being monozygotic was calculated to be 0.99 according to the method of Smith and Penrose (1955).

The serum was negative for muscle striation binding globulin and lupus erythematosus factor in all family members, and was positive for antinuclear globulin in the patient and her mother. Rheumatoid factor was positive in the serum of the healthy sister.

\section{CASE 2}

Case 2 is a 19 year old white woman. At the age of 11 years, she developed a sensation of tightness in the throat, ptosis, weakness of lips, arms, and legs, and difficulty in swallowing and breathing in a period of one month. Her condition was managed with oral administration of pyridostigmine bromide, with fairly good recovery of muscle strength initially. The effectiveness of the medica- tion gradually diminished, and, six months after the onset, she was severely weak, barely able to move her hands, with severe difficulty in swallowing and breathing, requiring tracheostomy and assisted respiration. Thymectomy was performed without immediate effect on muscle 0 strength. However, there has been gradual improvement of muscle strength. One year after the onset of the disease, $\stackrel{?}{-}$ she had an exacerbation with difficulty in breathing, but recovered after hospitalization without tracheostomy or $\overrightarrow{2}$ assisted respiration. At present, the patient is taking $60 \mathrm{mg}$ pyridostigmine bromide orally every four hours $\stackrel{\vec{S}}{\rightarrow}$ when awake, as well as aldactone and ephedrine. She has a slight weakness of the mouth and slurred speech, but the strength of the limb muscles is fairly good and there is no difficulty in swallowing.

The patient has a healthy twin sister. They are dizygotic twins, born with an individual placenta. Their \& parents and a 15 year old brother are in good health. There is no history of neuromuscular diseases in their. relatives.

\section{DISCUSSION}

Myasthenia gravis has been described in 21 sets of twins (Table). Both twins were affected in six sets, $\stackrel{\oplus}{\oplus}$ and one of the twins was affected in 15 sets. There or has been no report of occurrence of myasthenia gravis in triplets, quadruplets, or quintuplets.

TABLE

MYASTHENIA GRAVIS IN TWINS

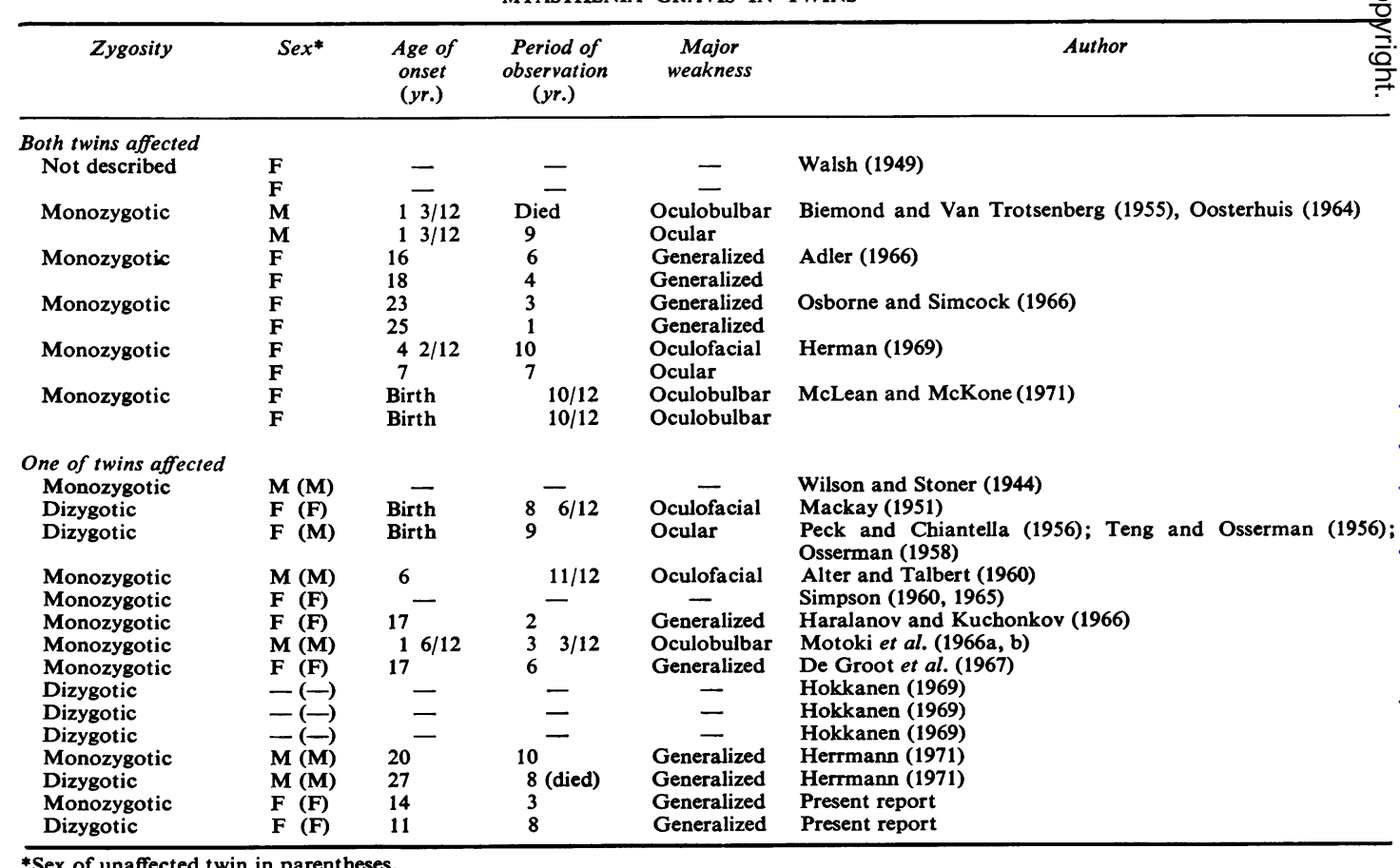

*Sex of unaffected twin in parentheses. 
Of the six sets in which both twins had myasthenia gravis, five were monozygotic, and none was dizygotic. In one set of twin sisters, there was no description of zygosity (Walsh, 1949). Onset of the disease varied from birth to 25 years, but the difference in the age of onset was less than three years in individual members of each set. The distribution of muscle weakness was also similar in each pair of twins. One patient developed hyperthyroidism four months after thymectomy, while her sister did not have thymectomy and remained euthyroid (Osborne and Simcock, 1966). Thymectomy was also performed in another set of twin sisters (Adler, 1966). In these three patients the thymus was hyperplastic. A brother of a set of myasthenic twin sisters died of myasthenia gravis at the age of 6 months (McLean and McKone 1971). The siblings of the other affected twins did not have evidence of myasthenia gravis, including 13 siblings of one set of twins (Osborne and Simcock, 1966), and four siblings of another set (Herman, 1966). The parents of the affected twins did not have myasthenia gravis, though the mother of one set had left ptosis since birth which did not respond to edrophonium or neostigmine administration (Herman, 1969).

Of the 15 sets of twins in which only one member of each set had myasthenia gravis, eight were monozygotic, and seven were dizygotic. In the dizygotic twins, the age of onset of the disease was at birth in two patients, at 17 years in one patient, and at 27 years in one patient. In the affected members of monozygotic twins the age of onset ranged from $1 \frac{1}{2}$ years to 20 years. The monozygotic twins were followed for one to 10 years, and it is possible that the unaffected member of each set of monozygotic twins may yet develop myasthenia gravis. One patient developed hyperthyroidism two years after the onset of myasthenia gravis, and later had a thymectomy, yielding a hyperplastic thymus (De Groot, Perlo, Gephart, and Schwab, 1967). Two additional patients also had thymectomy (Haralenov and Kutchoukov, 1966; Motoki, Chiba, Kawamura, Shioda, and Honda, 1966a; Motoki, Harada, Chiba, and Honda, 1966b). The curare test was negative in the unaffected member of three sets of twins, including one of the present cases(Mackay, 1951;Alter and Talbert, 1960). In one pair of dizygotic twins, the brother and sister both had epidermolysis bullosa congenita, but only the sister had myasthenia gravis, which was ocular and began at birth (Peck and Chiantella, 1956; Teng and Osserman, 1956; Osserman, 1958). They had a brother and a maternal male cousin who also had ocular myasthenia gravis, and the parents of these twins were first cousins. The father of one set of monozygotic twins had generalized myasthenia gravis which began at the age of 46 years, six years before the onset of generalized myasthenia gravis in one of his 17 year old twin daughters (Haralanov and Kutchonkov, 1966).

Excluding one set of twins whose zygosity is not known, myasthenia gravis in both members of twins occurred in five of 13 sets of monozygotic twins, but in none of seven sets of dizygotic twins. The difference is statistically significant $(P<0.03)$. In monozygotic twins, both twins were affected in four of eight sets of female twins, and one of five sets of male twins. In dizygotic twins, one of three males and three of five females had myasthenia gravis.

The familial incidence of myasthenia gravis is higher than could be accounted for by chance. The present authors have followed 702 patients with myasthenia gravis, of whom 27 patients in 12 families had familial disease (Namba, Brown, Muguruma, Brunner, and Grob, in press). This familial incidence of myasthenia gravis of $3.8 \%$ (95\% confidence limits, $2-5 \%$ ) is much greater $(\mathrm{P}<0.001)$ than the incidence of myasthenia gravis in the general population of less than $0.01 \%$ (Kurland and Alter, 1961). Environmental factors have not been identified as playing a role in the familial occurrence of myasthenia gravis. Familial aggregates of the disease have been found in blood relatives, some of whom have not lived together. One set of myasthenic monozygotic twin sisters lived separately in foster homes (Adler, 1966). There have been only two instances of myasthenia gravis in a wife and husband. However, a couple under our care developed the disease before marriage, and the onset of myasthenia gravis was not clearly described in the other couple (Curschmann, 1936). No geographic or racial predilection for myasthenia gravis or its familial occurrence has been recognized.

A high familial incidence of myasthenia gravis, and occurrence of the disease in both members of monozygotic twins but in none of dizygotic twins, suggest the role of a genetic factor in the pathogenesis of this disease, perhaps a rare recessive trait.

The authors are indebted to Dr. John A. Simpson for his kind suggestions, Dr. William T. McLean, Jr. for information on his patients, Dr. Aaron A. Alter and members of the blood bank for the blood group study, and Dr. Fred Rosner for the study of finger and palm prints. This study was supported by U.S. Public Health Service Grant NS 03464 from the National Institute of Neurological Diseases and Stroke, National Institutes of Health.

\section{REFERENCES}

Adler, E. (1966). Myasthenia gravis bei eineiigen Zwillingen. Disch. med. Wschr., 91, 396-397.

Alter, M., and Talbert, O. R. (1960). Myasthenia gravis in one monozygotic twin. Neurology (Minneap.), 10, 793-798. 
Biemond, A., and van Trotsenburg, L. (1955). Over congenitale en infantile myasthenie. Maandschr. Kindergeneesk., 23, 155-164.

Curschmann, H. (1936). Myasthenia gravis pseudoparalytica. In Handbuch der Neurologie, vol. 16, pp. 1005-1022. Edited by Bumke, O., and Foerster, O. Springer: Berlin.

De Groot, L. J., Perlo, V., Gephert, T., and Schwab, R. (1967). Remission of myasthenia and thyrotoxicosis after thymectomy. Ann. intern. Med., 67, 1042-1044.

Haralanov, H., and Kutchonkov, M. (1966). Myasthénie familiale (père et fille) avec hyperplasie du thymus. Résultats thérapeutiques spectaculaires avec rayons ' $x$ ' et thymectomie. Rev. neurol., 114, 437-442.

Herman, M. N. (1969). Familial myasthenia gravis: Report of a case in identical twins and review of family aggregates. Arch. Neurol. (Chic.), 20, 140-146.

Herrmann, C., Jr. (1971). The familial occurrence of myasthenia gravis. Ann. N.Y. Acad. Sci. (in press).

Hokkanen, E. (1969). Myasthenia gravis. A clinical analysis of the total material from Finland with special reference to endocrinological and neurological disorders. Ann. clin. Res., 1, 94-108.

Kurland, L. T., and Alter, M. (1961). Current status of the epidemiology and genetics of myasthenia gravis. In Myasthenia Gravis. The Second International Symposium Proceedings, pp. 307-336. Edited by H. R. Viets. Thomas: Springfield.

Mackay, R. I. (1951). Congenital myasthenia gravis. Arch. Dis. Childh., 26, 289-293.

McLean, W. T., Jr., and McKone, R. C. (1971). Congenital myasthenia gravis with crises in newborn twins. Neurology (Minneap.), 21, 450-451.

Motoki, R., Chiba, A., Kawamura, T., Shioda, Y., Honda, K. (1966a). Juvenile myasthenia gravis. Jap. J. thorac. Surg., 19, 642-648.
Motoki, R., Harada, M., Chiba, A., Honda, K. (1966b). A case of myasthenia gravis of identical twin brothers. Int. Surg., 45, 674-677.

Namba, T., Brown, S. B., Muguruma, M., Brunner, N. G., and Grob, D. (1971). Familial myasthenia gravis: Report of 27 patients in 12 families and review of 161 patients in 72 families. Arch. Neurol. (Chic.) (in press).

Oosterhuis, H. J. G. H. (1964). Studies in myasthenia gravis. Part J. A clinical study of 180 patients. J. neurol. Sci., 1, 512-546.

Oppenheim, H. (1898). Lehrbuch der Nervenkrankheiten für Aerzte and Studirende, p. 716. 2nd edn. Karger: Berlin.

Osborne, D., and Simcock, J. (1966). Myasthenia gravis in identical twins. Brit. med. J., 1, 1025-1026.

Osserman, K. E. (1958). Myasthenia Gravis, p. 255. Grune and Stratton: New York.

Peck, S., and Chiantella, S. (1956). Epidermolysis bullosa congenita in twins. Myasthenia gravis (girl). Arch. Derm. Syph. (Chic.), 73, 625-626.

Simpson, J. A. (1960). Myasthenia gravis: A new hypothesis. Scot. med. J., 5, 419-436.

Simpson, J. A. (1965). Myasthenia gravis. In Biochemical Aspects of Neurological Disorders, 2nd series, pp. 53-72. Edited by J. N. Cumings and M. Kremer. Blackwell Scientific Publications: Oxford.

Smith, S. M., and Penrose, L. S. (1955). Monozygotic and dizygotic twin diagnosis. Ann. hum. Genet., 19, 273-289.

Teng, P., and Osserman, K. E. (1956). Studies in myasthenia gravis: neonatal and juvenile types. J. Mt Sinai Hosp., 23 , 711-727.

Walsh, M. N. (1949). Cited in Levin, P. M. (1949). Congenita $\bar{b}$ myasthenia in siblings. Arch. Neurol. Psychiat. (Chic.), 62 745-758.

Wilson, A., and Stoner, H. B. (1944). Myasthenia gravis: a consideration of its causation in a study of fourteen cases Quart.J. Med., 13, 1-18. 